\title{
Visual Field Alteration Revealing Haschimoto Thyroiditis
}

\author{
Bouchra Tamym*, Imane Chabbar, Tarik Bouzouba, Souhaila Karmoun, Amina Berraho
}

Ophtalmologie B, hôpital des spécialités de Rabat, Morocco

DOI: $\underline{10.36347 / \text { simcr.2020.v08i06.009 }}$

| Received: 02.06.2020 | Accepted: 10.06.2020 | Published: 18.06.2020

*Corresponding author: Tamym Bouchra

Abstract

Hashimoto's thyroiditis is a chronic autoimmune inflammatory disease in which the ocular involvement is not very marked; we report the case of an alteration of the visual field revealing Hashimoto's thyroiditis.

Keywords: Visual Alteration Revealing Haschimoto.

Copyright @ 2020: This is an open-access article distributed under the terms of the Creative Commons Attribution license which permits unrestricted use, distribution, and reproduction in any medium for non-commercial use (NonCommercial, or CC-BY-NC) provided the original author and source are credited.

\section{INTRODUCTION}

Hashimoto's thyroiditis, or lymphocytic thyroiditis, was first described in 1912 by the Japanese Hakaru Hashimoto; as a chronic organ-specific autoimmune inflammatory disease [1]. Currently considered to be the most common autoimmune disease $[2,3]$, the most common endocrine disorder and the most common cause of hypothyroidism $[4,5]$.

Here we report a case of Hashimoto's thyroiditis revealed during an assessment for visual field disturbance.

\section{Clinical Case}

We report the case of a 26 years old woman, with no particular pathological history, who consults for reduced visual acuity of the right eye, with paresthesias such as tingling of the hemi left body. The neurological examination was in favor of an extrapyramidal syndrome.

The ophthalmological examination showed a visual acuity at $5 / 10$ of the right eye, not improved by optical correction, 10/10 at the level of the left eye. The examination of the anterior segment is normal. And a normal fundus (Figure 1).

The patient received a VEP / ERG with normal results. The visual field study revealed an alteration of the right central visual field (Figure 2), normal on the left side (Figure 3). Macular OCT was normal (Figure 4). Cerebro-medullary MRI was normal. Lumbar puncture was normal.
The ORL examination did not show any goiter; thyroid checkup: T3, T4, TSH ultrasensitive were normal, moreover anti-thyroglobulin antibodies were very high. antithyroperoxidase antibodies (antiTPO) were high and the sedimentation rate was normal. Our patient underwent a salivary gland biopsy with normal results.

Our patient received a bolus of SOLUMEDROL $1 \mathrm{~g} /$ day for 03 days with oral relay $(60 \mathrm{mg} / \mathrm{D})$ with progressive degression associated with an immunosuppressive treatment based on IMUREL. The ophthalmological examination at two months of treatment: visual acuity of the right eye at $10 / 10$, with normalization of the right visual field (Figure 5).

\section{DiscuSSION}

Hashimoto's thyroiditis is a chronic inflammation of witch the etiopathogenesis is not yet fully defined $[1,6]$. There is no international classification of autoimmune thyroid disease that clearly defines Hashimoto's disease. Certain definitions are based on the anatomopathological study of the thyroid [7].

Histologically; it is characterized by lymphocytic infiltration of the thyroid. Clinically, Hashimoto's thyroiditis is most often asymptomatic [8, 9]. Affects women five to seven times more than men $[10,11,12]$.

In its classic form (goitrous autoimmune thyroiditis), the patient may present with diffuse, sometimes asymmetrical, painless goiter, of firm or elastic consistency [13, 14]. 
Orbitopathy combining exophthalmos, oculomotricity disorders, palpebral retraction, may be associated with Hashimoto's disease, although it is more common in Graves' disease. Hasimoto's thyroiditis can also be associated, in the same individual or in relatives, with other autoimmune diseases such as Graves' disease, type 1 diabetes, rheumatoid arthritis, systemic lupus erythematosus, myasthenia, anemia pernicious [15]. In our patient, it was the alteration of the visual field that made it possible to investigate further in favor of Hashimoto's thyroiditis.

Different observations of encephalopathies have also been reported [16, 17]. This involvement is rare and is currently poorly defined. The neurological manifestations are varied such as generalized seizures [18, 19], ataxia [20-23], myoclonus [19 24], focal neurological deficits [19], phasic disorders, confusional states [19], extra pyramidal signs (choreic movements, hypokinesia, rigidity, tremors [21]) Psychiatric manifestations can be associated with neurological disorders.

The pathophysiology of this corticosensitive encephalopathy is poorly understood, but it could be either autoimmune processes involving neuronal antigens in parallel with autoimmune thyroid damage, or vasculitis concerning small arteries [16]. The role of dysthyroidism is unlikely, since the majority of the patients listed have euthyroidism [25].

An increase in the level of anti-TPO and antiTG autoantibodies in the serum associated with thyroiditis in the form of a hypoechogenic thyroid heterogeneous to ultrasound allows the positive diagnosis of TH [6]. The histological study is only indicated in the event of thyroid nodules or in the event of suspicion of an associated thyroid cancer [6].

First-line treatment; in central neurological disorders remains the intravenous bolus of methylprednisolone in high doses; Thus allowing a spectacular remission [19]. These boluses are relayed by long-term oral corticosteroid therapy. Other drugs can be used in case of ineffectiveness or contraindication, particularly immunosuppressants [26]. Immunoglobulins and plasma exchanges [27]. Multipurpose immunoglobulins are the most widely used treatments for peripheral neurogenic disorders [28].

Currently there is no consensus on the treatment of peripheral neurological complications of TH.

\section{CONCLUSION}

Dysthyroid ophthalmopathy corresponds to the ophthalmological disorders encountered in various thyroid diseases, in particular Graves' disease and Hashimoto's thyroiditis. The severity of this lesion does not depend on the clinical and biological thyroid status and its evolution.

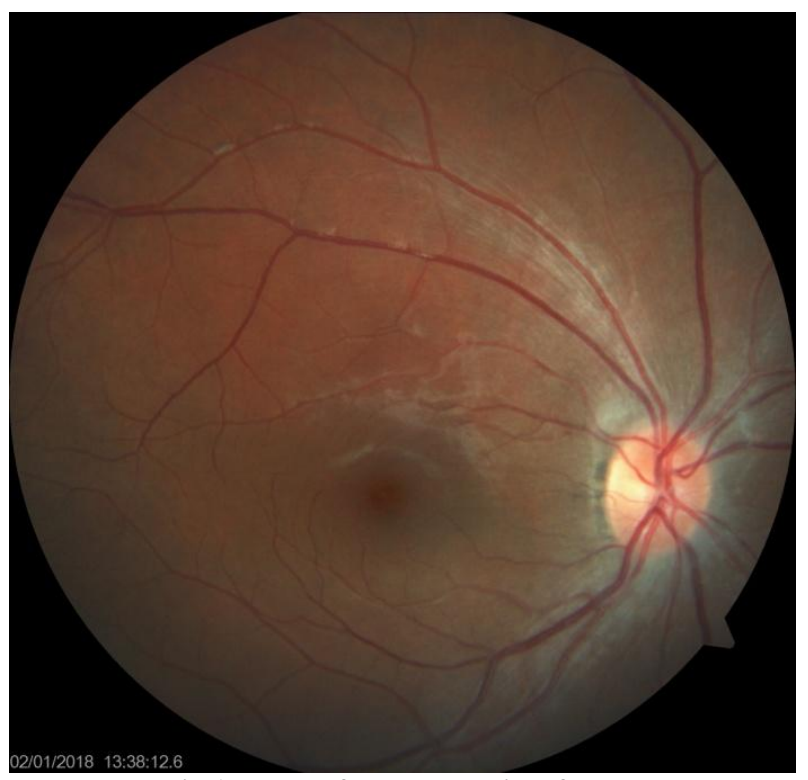

Fig-1: Image of the normal right fundus

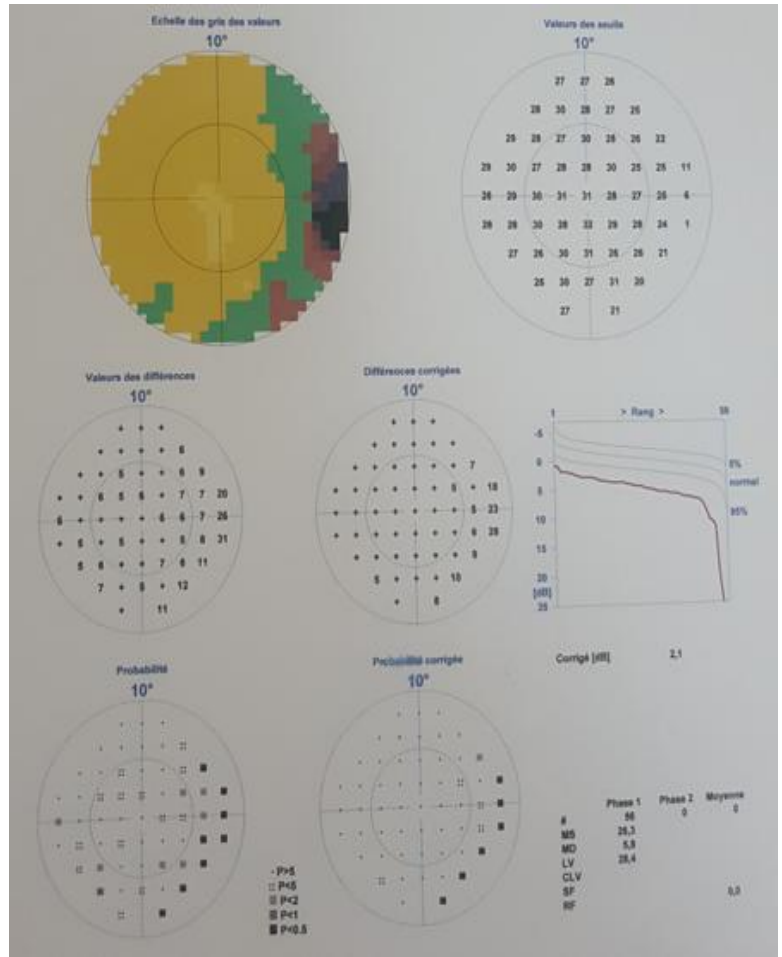

Fig-2: Visual field of the right eye showing a medium to deep Alteration of the central hemichamp without repercussion on the foveolar zone 


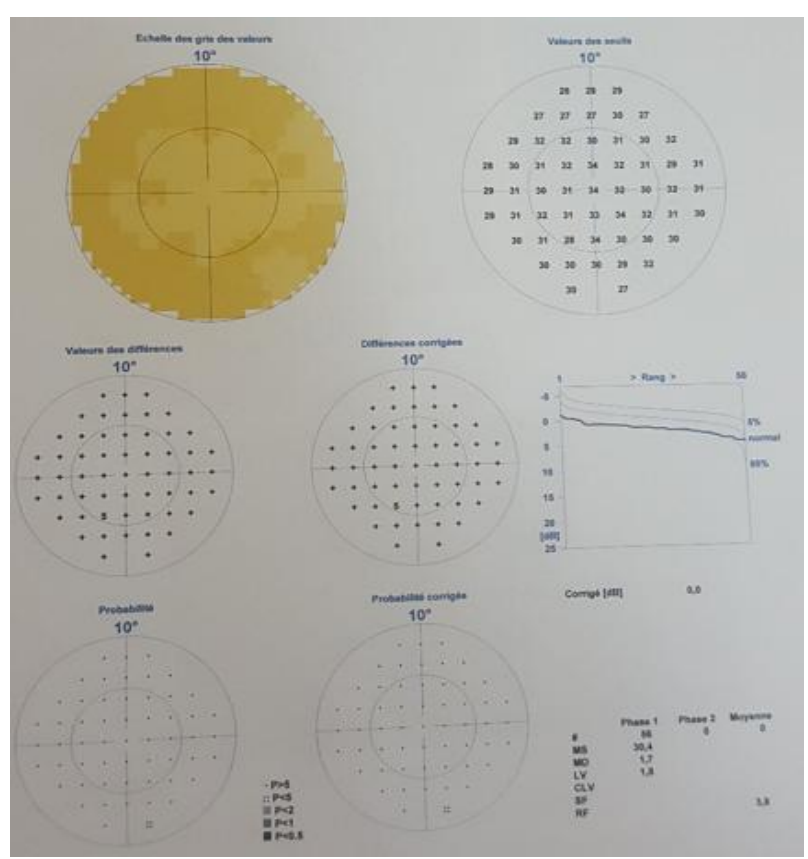

Fig-3: Normal Visual field of the left eye

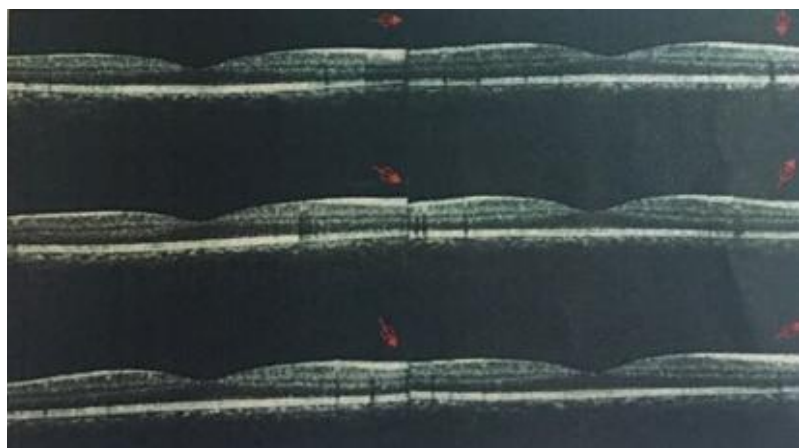

Fig-4: Normal right eye macular OCT

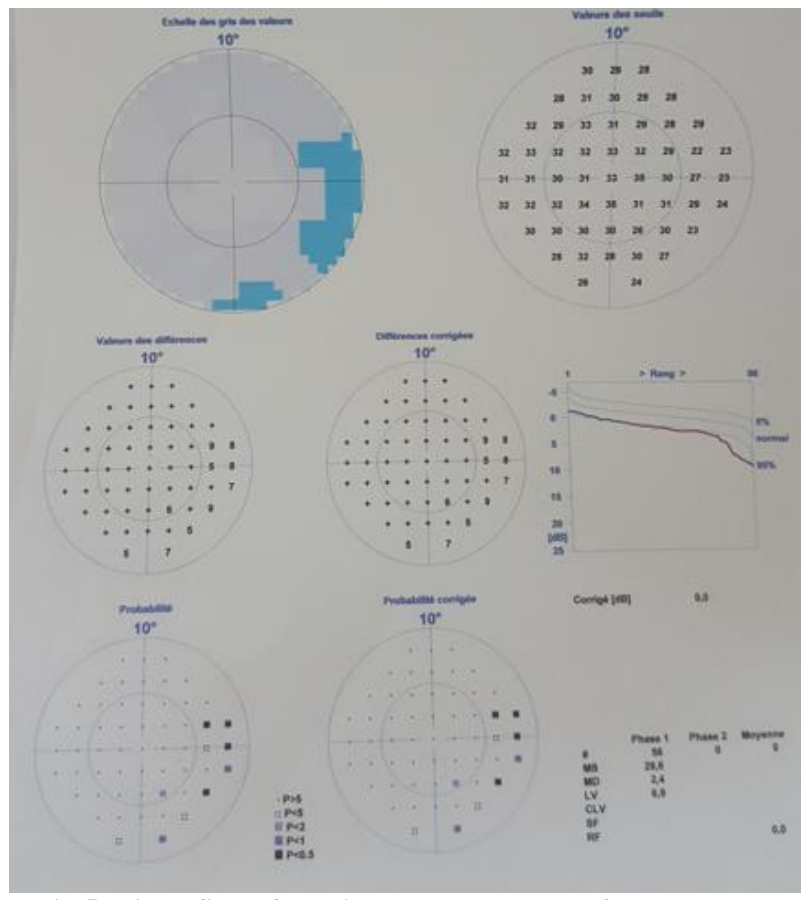

Fig-5: Visual field of the right eye two months after treatment showing a reduction in temporal retinal sensitivity without a localized deficit (relatively normal visual field)

\section{REFERENCES}

1. Hahsimoto H. Zur Kenntniss der lymphomatösen Veränderung der Schilddrüse (Struma lymphomatosa). Arch Klin Chir Ver Dtsch Z Chir. 1912:219-48.

2. Jacobson DL, Gange SJ, Rose NR, Graham NM. Epidemiology and estimated population burden of selected autoimmune diseases in the United States. Clinical immunology and immunopathology. 1997;84(3):223-43.

3. Grossi A, Crinò A, Luciano R,Lombardo A, Cappa M, Fierabracci A. Endocrine autoimmunity in Turner syndrome. Italian journal of pediatrics. 2013;39(1):79.

4. Delemer B, Aubert J-P, Nys P,Landron F, Boué S. An observational study of the initial management ofhypothyroidism in France: the ORCHIDÉE study. European journal of endocrinology. 2012:EJE-11-1041.

5. Garmendia Madariaga A, Santos Palacios S, Guillén-Grima F, Galofré JC. The incidence and prevalence of thyroid dysfunction in Europe: a metaanalysis. The Journal of Clinical Endocrinology \& Metabolism. 2014;99(3):923-31.

6. Radetti G. Clinical aspects of Hashimoto's Thyroiditis. Endocr Dev. 2014; 26:158-70.

7. Brain L, Jellinek EH, Ball K. Hashimoto's disease and encephalopathy. Lancet. 1966;2:512-4

8. Weetman A, McGregor A. Autoimmune thyroid disease: further developments in our understanding.Endocrine reviews. 1994;15(6):788830.

9. Pantuck AJ, Belldegrun AS, Figlin RA. Nephrectomy and interleukin-2 for metastatic renal-cell carcinoma. New England Journal of Medicine. 2001;345(23):1711-2.

10. Dayan CM, Daniels GH. Chronic autoimmune thyroiditis. New England journal of medicine. 1996;335(2):99-107.

11. Vanderpump M, Tunbrldge W, French J, Appleton D, Bates D, Clark F. The incidence of thyroid disorders in the community: a twenty- year follow- up of the Whickham Survey. Clinical endocrinology. 1995;43(1):55-68.

12. Doniach D, Bottazzo G, Russell R.6 Goitrous autoimmune thyroiditis (Hashimoto's disease). Clinics in endocrinology and metabolism. 1979;8(1):63-80.

13. Sostre S, Reyes M. Sonographic diagnosis and grading of Hashimoto's thyroiditis. Journal of endocrinological investigation. 1991;14(2):115-21.

14. Nordmeyer JP, Shafeh TA, Heckmann C. Thyroid sonography in autoimmune thyroiditis. A prospective study on 123 patients. Acta endocrinologica. 1990;122(3):391-5.

15. Vaidya B, Pearce S. The emerging role of the CTLA-4 gene in autoimmune endocrinopathies. European Journal of Endocrinology. 2004;150(5):619-26. 
16. Kothbauer-Margreiter I, Sturzenegger M, Komor J, Baumgartner R, Hess C. Encephalopathy associated with Hashimoto thyroiditis: diagnosis and treatment. Journal of neurology. 1996;243(8):585-93.

17. TROCELLO J-M. Encéphalopathiecorticosensible avec anticorps antithyroïdiens dite encéphalopathie deHashimoto: faculté de Médecine Paris-Ouest, Université Paris V; 2001.

18. Ferracci F, Carnevale A. The neurological disorder associated with thyroid autoim munity. J Neurol. 2006;253:975-984

19. Montagna G, Imperiali M, Agazzi P, D'Aurizio F, Tozzoli R, Feldt-Rasmussen U. Hashimoto's encephalopathy: A rare proteiform disorder. Autoimmun Rev. 2016 Feb 3. pii: S15689972(16)30010-6.

20. Lee HJ, Jeon K, Lee JY, Lee JE, Bae DW, Oh YS. Ocular flutter and ataxia without cognitive impairment associated with steroid-responsive encephalopathy associated with autoimmune thyroiditis (SREAT). J Neurol Sci. 2015 Dec 15;359(1-2):86-7.

21. Matsunaga A, Ikawa M, Fujii A, Nakamoto Y, Kuriyama M, Yoneda M. Hashimoto's Encephalopathy as a Treatable Adult-Onset Cerebellar Ataxia Mimicking Spinocerebellar Degeneration. Eur Neurol. 2013;69(1):14-20
22. Nakagawa H, Yoneda M, Fujii A, Kinomoto K, Kuriyama M. Hashimoto's encephalopathy presenting with progressive cerebellar ataxia. J Neurol Neurosurg Psychiatry. 2007 Feb;78(2):1967

23. Tang Y, Chu C, Lin MT, Wei G, Zhang X, Da Y. Hashimoto's encephalopathy mimickingspinocerebellar ataxia. J Neurol. 2011 Sep;258(9):1705-7

24. Arya R, Anand V, Chansoria M. Hashimoto encephalopathy presenting as progressive myoclonus epilepsy syndrome. Eur J Paediatr Neurol. 2013 Jan;17(1):102-4.

25. Cantón A, de Fàbregas O, Tintoré M, Mesa J, Codina A, Simó R. Encephalopathy associated to autoimmune thyroid disease: a more appropriate term for anunderestimated condition? Journal of the neurological sciences. 2000;176(1):65-9.

26. Kirshner HS. Hashimoto's encephalopathy: A brief review. Curr Neurol Neurosci Rep. 2014Sep;14(9):476.

27. Chong JY, Rowland LP, Utiger RD. Hashimoto encephalopathy: syndrome or myth? Arch Neurol. 2003Feb;60(2):164-71.

28. Reisin RC, Zurrú C, Buso C, Marchesoni C, Pardal AM, Jadzinsky M. Multifocal motor neuropathy, type 1 diabetes and asymptomatic Hashimoto's thyroiditis: an unusual association. Neuromuscul Disord. 2005 May;15(5):358-60. 